\title{
Towards Conceptual Coherence in the Research on Mathematics Learner Identity: a Systematic Review of the Literature
}

DOI:

10.1007/s10649-018-9819-2

\section{Document Version}

Accepted author manuscript

Link to publication record in Manchester Research Explorer

Citation for published version (APA):

Radovic, D., Black, L., Williams, J., \& Salas, C. (2018). Towards Conceptual Coherence in the Research on Mathematics Learner Identity: a Systematic Review of the Literature. Educational Studies in Mathematics, 99(1), 21-42. https://doi.org/10.1007/s10649-018-9819-2

\section{Published in:}

Educational Studies in Mathematics

\section{Citing this paper}

Please note that where the full-text provided on Manchester Research Explorer is the Author Accepted Manuscript or Proof version this may differ from the final Published version. If citing, it is advised that you check and use the publisher's definitive version.

\section{General rights}

Copyright and moral rights for the publications made accessible in the Research Explorer are retained by the authors and/or other copyright owners and it is a condition of accessing publications that users recognise and abide by the legal requirements associated with these rights.

\section{Takedown policy}

If you believe that this document breaches copyright please refer to the University of Manchester's Takedown Procedures [http://man.ac.uk/04Y6Bo] or contact uml.scholarlycommunications@manchester.ac.uk providing relevant details, so we can investigate your claim.

\section{OPEN ACCESS}




\title{
Running head: Conceptual Coherence in Research on Mathematics Learner Identity
}

Radovic Mathematics identity literature review

\section{Towards Conceptual Coherence in the Research on Mathematics Learner Identity: a} Systematic Review of the Literature

\author{
Darinka Radovic ${ }^{1}$, Laura Black ${ }^{2}$, Julian Williams $^{2}$ \& Christian E. Salas ${ }^{3}$ \\ ${ }^{1}$ Center for Mathematics Modeling, Universidad de Chile, Beauchef 851, Santiago, Chile. \\ ${ }^{2}$ School of Education, The University of Manchester, Oxford Road, Manchester, M13 9PL, \\ UK \\ ${ }^{3}$ Laboratorio de Neurociencia Cognitiva y Social (LaNCyS), Escuela de Psicología, \\ Universidad Diego Portales, Vergara 275, Santiago, Chile. \\ Acknowledgements: The work of the first author was funded by the National Commission \\ for Scientific and Technological Research in Chile (CONICYT) and by the Center for \\ Mathematical Modeling through a Basal project (CMM) and Unité Mixte Internationale \\ UMI CNRS 2807.
}

Corresponding author: Darinka Radovic - ORCID: 0000-0002-5489-6098

E-mail: dradovic@dim.uchile.cl

Telephone: +56229780515 


\begin{abstract}
This paper presents the results of a systematic review of the empirical literature, reported in research journals, on Mathematics Learner Identity (MLI). In the mathematics education research field, arguments have been made that the conceptualisation of Mathematics Identity (MI) is inconsistent and this makes the literature as a whole incoherent. This study aims to summarize how the concept has been employed and to develop an integrative model for analysing concept-definitions and concept-operationalizations of MLI. An analysis of 69 papers revealed 3 main dimensions that characterized how identity is conceptually defined in any research literature (social/subjective, enacted/representational and change/stability) and 5 main categories that describe how the literature has implemented these dimensions operationally (identity as individual attributes; identity as narratives; identity as a relationship with specific practices; identity as ways of acting; and identities as afforded and constrained by local practices). An emphasis on representational aspects of identities, particularly during higher education, and enacted and practice-related identities during primary and secondary education research was found. The discussion shows how the field would be clarified if studies made their choices of conceptualisation clear in terms of these dimensions and categories, and if research as a whole becomes more aware of restrictions/limitations in identity research, particularly at different points of the educational trajectory of students.
\end{abstract}

Keywords: Learner identity; Mathematics education; Mathematical identities; Literature review 


\section{Introduction}

Over the last two decades numerous studies in mathematics education have used the concept of identity, or "mathematical identity/ies" (MIs), in order to understand learning and development. Proof of its increased popularity is shown in the publication of books (e.g., Black, Mendick \& Solomon, 2008; Solomon, 2008; Walls, 2009) and a journal special issue (Mathematics Education Research Journal, 2015, volume 27, issue 1) targeting the topic. There are several reasons that explain the growing interest in this concept. For example, exploring how students identify with mathematics can offer valuable insights into the affective aspects of the relationship of the learner or teacher with mathematics (Hannula, 2012) and how a personal relationship with the subject develops over time (e.g., Walls, 2009). Perhaps more importantly, identity(ies) can be a useful tool in exploring students' difficulties in engaging with mathematical activity (e.g., Solomon, 2007), or understanding how identifying with some social categories (e.g., gender, race) can negatively influence mathematical engagement (e.g., Nasir \& Cobb, 2007).

Despite the indisputable relevance of the concept of identity, there are some important difficulties in its use for applied research. In social sciences nearly every scholar who works with the concept of identity complains about its slippery and confusing nature (Wetherell, 2010). In mathematics educational research the same concern exists, with critics referring to the absence of clear definitions and a lack of operationalization that explicitly addresses how the concept is used (Bishop, 2012; Brubaker \& Cooper, 2000; Cobb, Gresalfi \& Hodge, 2009; Sfard \& Prusak, 2005). This problem may be related to the fact that identity has been employed by authors coming from contrasting paradigms. For example, whilst some have explored affect and individual academic decisions (e.g., Eccles, 2009) others have targeted socio-political aspects (e.g., Boaler, 1999a; Sfard \& Prusak, 2005). So far, researchers have used a wide range of conceptualisations of identity which, coming from diverse epistemologies, have resulted in a relatively small field [Mathematics Education Research] overcrowded by numerous, inconsistent approaches (Darragh, 2016).

Recently, researchers concerned with these issues have begun to develop more suitable precise definitions of MI, as well as more explicit analytical frameworks (e.g., Cobb, 
Gresalfi \& Hodge, 2009; Sfard \& Prusak, 2005; Varela, Martin \& Kane, 2012). These attempts, although valuable, still present limitations. For example, in order to "solve" the problem of conceptual coherence, some authors have decided to adhere to one definition of identity and discard alternative or contesting points of view (e.g., Sfard \& Prusak and their definition of identity as narrative). Others have developed more comprehensive theoretical frameworks, but mainly based on their personal approaches to the problem (Cobb, Gresalfi \& Hodge, 2009; Varela, Martin \& Kane, 2012). A limitation of these attempts is that they are not based on the systematic study of how the concept of identity has been used in the literature. By not considering other available evidence in the field, the proposed frameworks are often influenced by researchers' theoretical allegiances and their personal or group local "languages".

Following the same concerns, Darragh (2016) recently published, in this same journal, the first systematic literature review of the concept's use in mathematics education research. She focused her review on the theoretical underpinnings of different conceptualizations, taking a critical stance and identifying how researchers' accounts are informed by the theory they adopt explicitly or otherwise. This article intends to increase the understanding of mathematics identity further by particularly focusing on Mathematics Learner Identities (MLI) and by considering how definitions are operationalized in research practice. Although theory is considered when exploring definitions, the main purpose of this analysis is to identify how identity is finally used for different purposes and with different methodological tools, an aspect that was not a focus of Darragh's review. In consequence, a key aspect of this paper is to develop a model of the main dimensions that need to be considered when analysing researchers' conceptualizations of MLIs. Therefore, three main research questions will guide this review: RQ1) what are the defining features shared by different conceptualisations of MLIs? RQ2) How can studies be grouped according to how different defining features are emphasized and operationalized? And RQ3) How are these groups of studies distributed in the study of MLIs at different stages of schooling? 


\section{Methodology}

\subsection{Sample}

A systematic search of the concepts "identity" (identification/identities/identity) and "mathematics" (math/maths/mathematical) was carried out using several search engines [Web of Science, ERIC, BEI, and PsychInfo] and journals specialized in Mathematics Education Research [Educational Studies in Mathematics, For the Learning of Mathematics, International Journal of Science and Mathematics Education, Journal for Research in Mathematics Education, Journal of Mathematical Behavior, Research in Mathematics Education, Mathematical Thinking and Learning $\left.{ }^{1}\right]$. Only peer reviewed articles that included both key concepts in their title or abstract were considered as part of the initial sample.

From the initial search 543 articles that had both key words were selected. As a second step, and in contrast with the methodology used by Darragh, literature reviews or theoretical discussion with no data and articles focusing on teachers' MIs (no students identities) were excluded from the sample. In order to be able to explore how conceptualisations and theoretical definitions were anchored in concrete methodological approaches we included only studies that presented and analysed data. We decided to exclude articles focusing on teachers' MIs because we considered that differences between the activity of teaching and the activity of learning would add excessive complexity to the definition and operationalization of identity. Besides, research on teachers' identities has shown that moving into teaching requires a major shift from students' identities to professional identities (e.g., Flores \& Day, 2006; Sutherland, Howard \& Markauskaite, 2010). In consequence, we thought that arguably "teachers' mathematical identities" and “students' mathematical identities" were different concepts, thus, deciding to exclusively focus on the second one. In addition, articles that used the term identity as a mathematical concept (e.g., trigonometric identities, series identities), used identity to signal a structural category (e.g., gender and race/ethnic) with no relation to MIs and papers that focused on

\footnotetext{
1 These journals were chosen because they were considered highly influential in Mathematics Education Research. Recently they were listed as some of the highest ranked journals in the field (Nivens \&. Otten, 2017).
} 
another discipline (studies on STEM were retained) were also excluded. Finally a total of 69 articles were considered for analysis.

\subsection{Analysis}

A list of the 69 selected articles was exported to an excel file, with basic information (title, source, keywords and abstract) (a complete list of these articles is included in appendix 1). Following a "Thematic Synthesis" model (Thomas \& Harden, 2008) definitions of identity [and associated conceptualizations and operationalizations] were analysed. This model follows a similar approach to grounded theory, but uses studies as objects of analysis (rather than primary qualitative data as in Strauss \& Corbin, 1998). Initially, in the analysis there is a close focus on the data itself only later to build up more abstract conceptualisations. In other words, it moves from line-by-line coding towards descriptive and analytical coding (Thomas \& Harden, 2008).

The first step of the procedure was to extract information from papers in the form of literal quotes, gathering small paragraphs on definitions of identity (mean 170 words), description of research purpose and research questions (mean 90 words), and methodology (mean 220 words). These literal quotes were used as raw data for analysis. The initial step of analysis focused on identifying defining features referred to by studies as central to their conceptualisation of identity (RQ1, see example in table 1). Initially this process remained closely attached to the data, using strategies like highlighting central words/concepts and paraphrasing (table 1, step 1). This procedure led to codes that were constantly refined, in order to advance the analysis towards the generation of more general categories (Strauss \& Corbin, 1998). Constant comparison between studies was central in this step. As a main outcome of this analysis, papers were briefly described in terms of which defining features were considered in their conceptualization and how they were accounted for (table 1, step 2). A description of their emphasis and how each of them was operationalized was also produced considering the information extracted from each paper's stated research purpose and methodology (table 1, step 3). 
Table 1:

Worked example of analysis procedure

\begin{tabular}{|c|c|c|}
\hline $\begin{array}{l}\text { Step 1: } \\
\text { Quote of Definition of Identity }\end{array}$ & $\begin{array}{l}\text { Step 2: } \\
\text { Analysis of defining } \\
\text { Features }\end{array}$ & $\begin{array}{l}\text { Step 3: } \\
\text { Emphasis: } \\
\text { Purpose - } \\
\text { Operationalization }\end{array}$ \\
\hline $\begin{array}{l}\text { Study A: I define identity as a dynamic view of } \\
\text { self, negotiated in a specific social context and } \\
\text { informed by past history, events, personal } \\
\text { narratives, experiences, routines, and ways of } \\
\text { participating. An identity is who one is in a } \\
\text { given community and, as such, is both } \\
\text { individually and collectively defined (...) Note } \\
\text { that this definition includes a person's ways of } \\
\text { talking, acting, and being and the ways in } \\
\text { which others position one with respect to } \\
\text { mathematics. Moreover, a mathematics identity } \\
\text { is dependent on what it means do mathematics } \\
\text { in a given community, classroom, or small } \\
\text { group. As such, identity is situated; learned; } \\
\text { stable and predictable, yet malleable; and is } \\
\text { both individual and collective. }\end{array}$ & $\begin{array}{l}\text { - Social (who one is in a } \\
\text { particular community) AND } \\
\text { Subjective (view of self - } \\
\text { ideas of who one is). } \\
\text { - Process of Identity } \\
\text { construction: Identity as } \\
\text { learned / negotiated in } \\
\text { context. }\end{array}$ & $\begin{array}{l}\text { Purpose: Show how } \\
\text { identities are enacted at the } \\
\text { microlevel. Method: patterns } \\
\text { of social interaction, } \\
\text { microanalysis of discourse. } \\
\text { Emphasis on enactment and } \\
\text { social interactions. }\end{array}$ \\
\hline $\begin{array}{l}\text { Study B: Mathematics identity encompasses the } \\
\text { dispositions and deeply held beliefs that } \\
\text { individuals develop about their ability to } \\
\text { participate and perform effectively in } \\
\text { mathematical contexts and to use mathematics } \\
\text { to change the conditions of their lives. A } \\
\text { mathematics identity encompasses a person's } \\
\text { self understandings as well as how they are } \\
\text { constructed by others in the context of doing } \\
\text { mathematics. Therefore, a mathematics identity } \\
\text { is expressed in narrative form as a negotiated } \\
\text { self, a negotiation between our own assertions } \\
\text { and the external ascriptions of others. }\end{array}$ & $\begin{array}{l}\text { - Social as context and as } \\
\text { collectively defined (build } \\
\text { in the context of doing } \\
\text { mathematics and } \\
\text { constructed by others) AND } \\
\text { Subjective (self- } \\
\text { understanding). } \\
\text { - Process of identity } \\
\text { construction: As negotiation } \\
\text { between self and others } \\
\text { "ascriptions". }\end{array}$ & $\begin{array}{l}\text { Purpose and methods based } \\
\text { on life-stories, narrative } \\
\text { interviews. } \\
\text { Emphasis on representations } \\
\text { and subjective sense. }\end{array}$ \\
\hline
\end{tabular}

Note. Text in bold refers to the first step of analysis, where main concepts were highlighted. The studies used in this working example were: Study A (Bishop, 2012) and Study B (McGee \& Martin, 2011).

To answer RQ2, we identified how each paper emphasised and understood the relationship between different defining features of MLI operationally (step 2 and 3). This led to a categorisation of papers into different groups (step 3). Again, constant comparison between 
papers was central in defining these categories and in refining operational emphasis. Final categories and their descriptions are presented in the result section (see table 2).

As a next step, and in order to explore the distribution of the different emphases in research on different stages of schooling (RQ3), studies were categorised according to the age of their participants as reported by articles: school years (primary, middle-school, secondary/high school), transition between school and higher education (including longitudinal studies and studies focus on anticipation and interests) and higher education (undergraduate and postgraduate education). Finally, the frequency of the use of different conceptualisations of identity across stages of schooling was explored (RQ3). The analysis was led and performed by the first author, but the definition of general categories and grouping of papers alongside these categories were discussed with co-authors.

\section{Results}

\subsection{Descriptive results}

Consistent with Darragh's review (2016), empirical research published on MLI has increased steadily over the last two decades, and especially over the last 10 years. Half of the studies of our final sample focused on school education $(51 \%, n=35)$ and the other half on transition $(19 \%, n=13)$ and higher education $(30 \%, n=21)$. Most studies during school age concentrated on students at secondary level $(29 \%, n=20)$, with very few exploring mathematical identities in primary $(10 \%, n=7)$ and middle school $(12 \%, n=8)$.

It is interesting that over $70 \%(n=49)$ of the studies explored identity in relation to issues of equity (e.g., unequal access and underrepresentation). Gender was the most frequently addressed equity issue [ $54 \%, \mathrm{n}=37$ ] followed by ethnicity and race [ $40 \%, \mathrm{n}=27]$. While most of these articles considered class or socioeconomic status (SES) as an intersecting dimension with ethnicity and gender, only one explored the effect of class by itself and only three considered the intersection of all three social categories - gender, social class and ethnicity.

\subsection{What are the Defining Features of Identity?}


In relation to RQ1, we identified three main dimensions containing defining features of identity: a subjective/social dimension, a representational/enacted dimension and a change/stability dimension. In relation to the first dimension, a subjective notion of oneself was considered when authors mentioned in their conceptualization of identity subjects' senses or experiences, such as "sense of continuity", "sense of a place in the world", a "sense of being", a "sense of connection or belonging", a "self-view", or even as "selfdescriptions". Here, the notion of "sensations" positioned identity as a private experience of who one is. Alongside this same dimension, many studies conceptualized identity emphasizing its social aspect. Here, definitions often considered identities as "social products", something constituted by "social discourses", "a space in which discourses work and are worked". Another way in which the social aspect was considered was when definitions conceptualized identity as performed in social practice and recognized in these social spaces by others.

In relation to the representational/enacted dimension, we identified representational aspects when identity was defined by authors as mediated by discourse or language ${ }^{2}$. These discourses, or languages, were described as "concepts" (self-concepts), "discourses" and "narratives or stories about one-self". Studies that had an embodied/enacted view of identity described it in their definitions as expressed and performed in action, with no necessary mediation of language representations. This characteristic was often considered in studies through the idea of engagement in action, employing concepts such as "ways of being in action", "forms of participation", "forms of engagement" or "roles performed during activities". These concepts were used to stress how different ways of being in action may constitute different identities.

The last dimension we identified was the change/stability dimension and this related to how the process of change was described (if considered) in a conceptualization of MLI. In most studies we identified a view of identity as being constructed through a process, and consequently, learnt and open to change. This malleable quality implied that the temporary nature of an MLI is relevant when conceptualizing and operationalizing identity, and

\footnotetext{
${ }^{2}$ We used the code representational when identity was seen as constructed using symbolic resources or "representations", or when it was defined as a semiotically mediated construction. Most studies do not see these symbolic resources as representation of an inner-identity (a mental construct) as discussed by Sfard (2006).
} 
therefore many studies explored how identities unfold across time. Some conceptualizations of MLI strongly adhered to this notion by explicitly defining identities as "fluid", "in process", "malleable" or "dynamic". Others that were less explicit explored how identity may change under certain circumstances only. Only very few studies explicitly stated that identities were relatively "stable personal factors" and even in these cases possibilities of change where explored.

A relevant aspect of reviewing conceptualisations of MLI refers to the theoretical/methodological problem of how the defining features of these dimensions relate to each other. This is not a minor issue since all articles included in this review considered more than one defining feature, and the articulation between these features was never simple or straightforward. In our opinion how each study articulates defining features can be described by addressing the following questions: How do we understand the relationship between two defining features that belong to the same dimension (intra- dimension: e.g., subjective/social)? and How do we understand the relationship between defining features of different dimensions (inter-dimension: e.g., enacted/change)? Regarding the first question (intra-dimension), a potential misunderstanding may arise from the way we understand what a dimension is. The reader might think, for example, that a dimension is structured by antagonistic and mutually exclusive poles, where a stronger emphasis in one pole (subjective) would imply a weaker consideration of the other (social). An alternative way to understand the relationship between two poles is to focus on the inherent tension that exist between them and how each author addresses and solves such tension when defining and operationalizing what $\mathrm{s} /$ he believes MLI is. This solution may involve recognising the authors' emphasis on one defining feature over the other, but it may also involve articulating the two "poles" in a way that connects them so that an emphasis on one implies an emphasis on the other. In relation to the second question -How do we understand the relationship between the defining features, which belong to different dimensions? This question is less problematic than the previous one, since authors often combined defining features from the three different dimensions (e.g., change/enacted) when conceptualizing and operationalizing MLIs. Each study typically articulated the defining features of these dimensions more clearly through its operationalisation of MLI in empirical analysis. Given there are multiple possible combinations of the different defining features of our three 
dimensions (e.g., enacted/change, representational/subjective, subjective/stable and so on) and given their methodological grounding, we created categories of how MLI is conceptualised and operationalised both empirically and methodologically (step 3) and we present these categories in the next section.

\subsection{Different Conceptual and Methodological Emphases in Approaches to Identity}

In relation to RQ2 [How can different studies be grouped according to how defining features were emphasized and operationalized?], we identified five different categories of studies (see table 2).

Table 2:

Categories and Operational Emphasis

\begin{tabular}{|c|c|c|c|}
\hline Named Category & $\begin{array}{l}\text { Emphasised } \\
\text { dimensions }\end{array}$ & $\begin{array}{l}\text { Operationalization and preferred } \\
\text { methodology }\end{array}$ & Examples \\
\hline $\begin{array}{l}\text { Identity as } \\
\text { individual } \\
\text { attributes }\end{array}$ & $\begin{array}{l}\text { Representational/ } \\
\text { Subjective }\end{array}$ & $\begin{array}{l}\text { Identity as levels of agreement with } \\
\text { different statements about oneself (e.g., } \\
\text { ability). Data collection through surveys. }\end{array}$ & $\begin{array}{l}\text { Andersen \& Ward, } \\
\text { 2014; Axelson, 2009; } \\
\text { Lesko \& Corpus, } \\
2006\end{array}$ \\
\hline $\begin{array}{l}\text { Identities as } \\
\text { Narratives }\end{array}$ & $\begin{array}{l}\text { Representational/ } \\
\text { Subjective-Social }\end{array}$ & $\begin{array}{l}\text { Identities as storied using social } \\
\text { discourses or social resources. Data } \\
\text { collection through narratives. }\end{array}$ & $\begin{array}{l}\text { Black et al., 2010; } \\
\text { Mendick, 2005; } \\
\text { Solomon, } 2012\end{array}$ \\
\hline $\begin{array}{l}\text { Identities as a } \\
\text { relationship with a } \\
\text { practice }\end{array}$ & $\begin{array}{l}\text { Representational/ } \\
\text { Social-Subjective }\end{array}$ & $\begin{array}{l}\text { Identities as sense of } \\
\text { belonging/membership. Data collection } \\
\text { through surveys/interviews. }\end{array}$ & $\begin{array}{l}\text { Campbell et al., 2012; } \\
\text { Darragh, 2013; Lim, } \\
\text { 2008; Tate \& Linn, } \\
2005\end{array}$ \\
\hline $\begin{array}{l}\text { Identities as ways } \\
\text { of acting }\end{array}$ & $\begin{array}{l}\text { Enacted/ Social- } \\
\text { Subjective }\end{array}$ & $\begin{array}{l}\text { Identities as acted in particular social } \\
\text { contexts. Data collection through } \\
\text { observations focused on social } \\
\text { interactions. }\end{array}$ & $\begin{array}{l}\text { Bishop, 2012; Black, } \\
\text { 2004; Turner et al., } \\
2013\end{array}$ \\
\hline $\begin{array}{l}\text { Identities as } \\
\text { afforded and } \\
\text { constrained by } \\
\text { local practices }\end{array}$ & $\begin{array}{l}\text { Representational/ } \\
\text { Social }\end{array}$ & $\begin{array}{l}\text { Focused on how local practices afford } \\
\text { particular identities. Case studies of these } \\
\text { practices - Mixed methods. }\end{array}$ & $\begin{array}{l}\text { Hodge, 2008; Horn, } \\
\text { 2008; Nassir \& Hand, } \\
2008\end{array}$ \\
\hline
\end{tabular}

\subsubsection{Identities as individual attributes}


The first group of studies was characterised by a definition of identity which emphasized the subjective end of our subjective/social dimension, a notion of oneself as consisting of individual attributes $(n=10,15 \%)$. These attributes also had a representational nature in that they are always discursively mediated and, in consequence, were predominantly investigated via self-reports (mainly surveys). Even though the social world was seen as an influence in the construction of MLIs, individuals were often considered as separate from their social context. Identities were generally defined in these studies as "self-views", "selfdescriptions", "self-concepts", "self-competence" or "self-esteem", and consequently these attributes were described as individually bound and relatively independent from the discipline.

There are three main features that define how this group of studies treated the concept of identity. Firstly, no major attention was given to the relationship between individuals' identities (subjective) and a particular situated mathematical activity (social). In this sense, the emphasis on subjective aspects in these studies excluded the social dimension to some extent. For example, the operationalization of MLIs as level of agreement with survey questions (e.g., "I am good at mathematics" or "I see myself as a mathematician") assumed there was only one way of doing mathematics (in which I am good or bad) or that there is only one type of mathematician (with which I identify/or not), independent of context. As a consequence, students were often described in terms of having or expressing quantifiable "levels" of identification.

Secondly, studies from this group tended to see individuals and their social contexts as separate entities, with social factors influencing students' personal variables (i.e., identity attributes). Thus, the process of identity construction was often explained as the individual's response to a social stereotype by "identity bifurcation" (i.e., separating oneself from the stereotyped activity), "identity correspondence" (i.e., seeing the "individual identity" as compatible with the stereotyped activity) (e.g., Lesko \& Corpus, 2006; Pronin, Steel \& Ross, 2004) or by developing “consistency of identities” (e.g., Andersen \& Ward, 2014; Boe, 2012; Hernandez et al., 2013).

Finally, most of these studies conceptualized mathematical identities as a malleable phenomenon (i.e., nearly all considered some form of change on the change/stable 
dimension). Although they were not explicit in defining identities as fluid (as other studies did), most described and explored how identity may change under certain circumstances. For instance, some of them demonstrated that the salience of a stereotype can be manipulated in experimental situations, and some authors even stated that an individual's ability to identify with mathematics could be facilitated or limited according to changes in context. However, the process by which an "individual identity" can change according to variation in context was rarely addressed, remaining a matter of debate. So, while some authors explicitly defined 'mathematical identities' -or "domain identity" according to their model- as a relatively "stable and enduring" "personal factor" (Hernandez, et al., 2013), others stated that the conceptualisation of identity as a stable phenomenon may need to be revised (Axelsson, 2009).

\subsubsection{Identities as narratives}

A second group of studies $(n=24,36 \%)$ emphasised the representational dimension of identity operationalized in the form of narratives. Most of these studies disagree with a view of identity as a personal attribute, stressing the relevance of cultural and social resources, which shape personal narratives of mathematical learners (i.e., they acknowledge the social as a defining feature from the subjective/social dimension). Some see these narratives as enactments of identity, constructed in the moment, and not a representation of an inner identity (see Sfard, 2006, for a discussion on this matter). Following this, narratives in this group were not only the object of study but also the method of choice to collect data. This has important theoretical and methodological implications since narratives are considered to be re-constructed during the process of recollection, thus preserving identities' dynamic and fluid quality.

Even though all studies included in this group emphasized representational [narrative] forms of identities and acknowledged that the subjective experience of identities was intrinsically related to social influences, variations in the emphasis placed on the social/subjective dimension were observed. One group of narrative studies stressed the subjective - self-understanding, self-reflection and subjects' agency in the construction of personal histories (within social constraints). Narratives within these studies were seen as used by students to manage stereotypes (McGee \& Martin, 2011), as tools for self- 
regulation (Black et al., 2010) or as an orchestration of multiple voices (Braathe \& Solomon, 2015; Solomon, 2012). In contrast, another group of narrative studies conceptualized these narratives as self-positioning in discursive spaces, with emphasis on social aspects and structural restrictions rather than individual agency. Here, narratives were conceived as a form of identity work, which captures the labour involved in negotiating dominant discourses that restrict what the individual sees as "possible and/or desirable" positions (Acher et al., 2013; Holmegaard, Madsen \& Ulriksen, 2014; Mendick, 2005). Some authors within this group also explored the social origins of such discourses (e.g., Epstein, Mendick \& Moreau, 2010; Mendick, 2005).

There are two further issues that deserve to be mentioned regarding the operationalization of identities as narratives. Firstly, when MLIs were defined as a narrative of a relationship between individuals and a mathematical activity, mathematics itself became a constructed phenomenon. Such a de-naturalisation of mathematics implied that there were as many mathematics as narratives, and that students could become active agents -either by contributing or resisting- in the construction of these practices of mathematics (e.g., Craigh, 2013; Solomon, Lawson \& Croft, 2011).

A second issue is the relevance of time as a structuring element of MLIs. Several authors included in their operationalizations the idea that identities unfold in time (Sfard \& Prusak, 2005), extending towards the future when aspirations or motives are narrated (Acher et al., 2012, Black et al., 2010), or becoming the product of a temporal tension when elements of the past, present and future become articulated in a narrative (Solomon, 2012). In this sense, this group of studies give more emphasis to change than the previous group.

\subsubsection{Identity as a relationship with a specific practice}

A third group of studies emphasized how identities were defined by the relationship that individuals established with a particular mathematical practice $(\mathrm{n}=8 ; 12 \%)$ (social), a relationship that was described mainly as subjective and representational. Most researchers from this group used self-report tools (interviews, narratives and surveys), while a few triangulated self-report data with observations of individuals during practice.

In contrast with the conceptualisation of identity as an individual attribute, which saw learners as somehow separated from their social environment, in this group subjective and 
social features were considered as unified in individuals' identities. Identities were conceived here as a "sense of belonging" or "forms of membership" (e.g., Solomon, 2007) and were impossible to understand without considering the collective and shared practice.

Since the emphasis was placed on representational resources regarding local practices, these studies stressed the situated nature of the process by which meaning is constructed, and defined identity development as a negotiation of meanings. This perspective about the social differs from narrative studies in that there is a greater emphasis on analysing how shared meanings are negotiated in a particular practice, with less interest in how big social discourses are negotiated. Although in this group of studies discourses or institutional practices are considered, they are often included via the analysis of their concrete manifestations in specific practices (e.g., schools with/without ability grouping; segregated/diverse classrooms, etc., as in Darragh, 2013; Solomon, 2007). As a consequence, the relationship of the student with the particular practice becomes the centre of focus. Although some of these studies used a narrative approach, these were not seen as the essence of identity, but simply a means to investigate the relationship of individuals with a practice.

Another difference between these and the narrative studies identified above relates to how central are notions of change, time and process in the constitution of identity. Studies that explored a sense of self in relation to practice tended to focus on observing identities in several dimensions, such as self-perceived competence (in comparison with definitions of competence in place in the specific context) or interests (in relation to the resources available in the specific practice). In this sense, these studies do not focus on change in the individual's trajectories or on the unfolding of identities in a timed-structured story as studies with a narrative view of identity do.

\subsubsection{Identities as ways of acting:}

The fourth category included studies that conceptualise MLIs as ways of acting $(\mathrm{n}=12$; $18 \%$, which shifted the focus from representational to enacted aspects. This perspective views participation as a constantly changing process where identities are negotiated in moment-by-moment interactions. Authors like Bishop (2012) have referred to these emerging identities as "micro-identities". Researchers who adhere to this perspective 
commonly use case studies and ethnographies as main methodologies in order to provide an in-depth account of students' enacted identities. Here, observed interactions between subjects is the main unit of analysis.

Studies that considered identities as ways of acting focused on students' "forms of subjectivisation" and "forms of participation". "Forms of subjectivisation" were operationalised as the way in which individuals positioned themselves in relation to others during conversations (Bishop, 2012; Heyd-Metzuyanim, 2013), while "forms of participation" were defined as the way in which individuals show they are able or unable to act in certain ways (Bishop, 2012; Turner et al., 2013). Both operationalisations also have a strong social emphasis in understanding students' positioning, thus by emphasizing enacted identities these studies are also unifying the subjective and social features of identity.

Another element that was shared by this group of studies was an emphasis on change and the process of identity development while interacting with others. Identity was seen as something fluid and changeable according to contextual influences, but also as an emergent process which can become crystallised. Evidence from longitudinal studies appears to support this claim, since it has been observed that repetitive patterns of interaction can restrict students' possible ways of acting, thus offering positions of increased or decreased competence and confidence (Bishop, 2012; Empson, 2003; Turner, Dominguez, Maldonado \& Empson, 2013) as well as positions with increased or decreased access to participation and resources (Bishop, 2012; Black, 2004).

\subsubsection{Identities as afforded and constrained by local practices}

A final group focused on the particular Identities afforded and constrained by local practices, in terms of the spaces offered for students to develop, narrate or enact particular identities $(n=14,20 \%)$. Here the subjective aspect of MLIs was not emphasized in the operationalization; instead, relevance was given to particular contexts and how they provided resources that made some identities possible. Most of these articles used case studies of particular shared practices, where different sources of data converged to develop an understanding of how practices worked and which identities they offered. As a consequence, mixed methods and ethnographies were methodologies of choice in these studies. 
At a practice level, studies often used a comparison of activities in relation to their social status (usually classed) as an analytical tool, and also explored whether students could identify or not with these practices. More specifically, researchers from this tradition were interested in investigating the normative identity(ies) of a particular practice, its particular constraints and affordances (Boaler, 1999b; Cobb, Gresalfi \& Hodge, 2009), how competence was defined by each practice (e.g., Hodge, 2008; Horn, 2008), and how different forms of engagement and identities were legitimised within each practice (e.g., Nasir \& Hand, 2008).

Findings from these studies have offered evidence on how varied contexts provide different available identities, in relation to which students need to position themselves. Different pedagogical practices (e.g., Cobb, Gresalfi \& Hodge, 2009; Hodge, 2008), cultural contexts such as classroom culture and culture at home (Anderson \& Gold, 2006; Chronaki, 2005; de Abreu, 1995) and social activities such as school mathematics and sports (Nasir \& Hand, 2008) are some of the contexts explored within these studies.

\subsection{Definitions of Identities at Different Stages of Schooling}

The final research question of this review looked at how different groups of studies of MLIs were distributed at different stages of schooling. In relation to primary education, we found a notable absence of studies recognising subjective representational identities (individual attributes, narratives and relationship with practice), with all studies focusing on either enacted identities (ways of acting) or examining the identities offered by the particular practice of the classroom (identities as afforded and constrained by local practices). This tendency is also observed during middle and secondary school, where these two categories of studies account for more than $60 \%$ of the articles (see figure 2 ). 


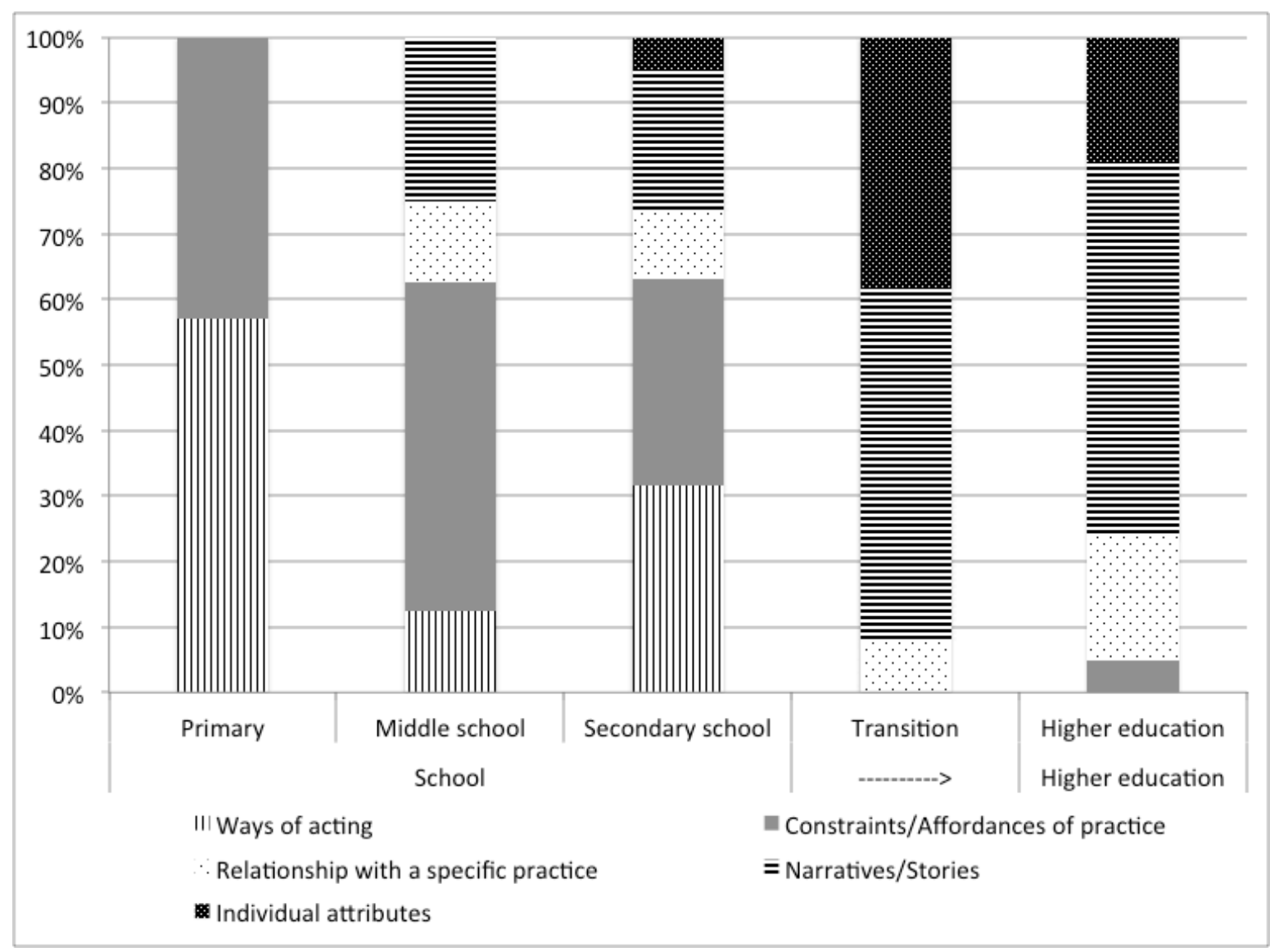

Figure 2: Identity Categories in different stages of schooling

In contrast to the predominance of studies exploring enacted and practice related identities in school education, most of the studies in higher education tended to focus on representational and subjective definitions of identity. More specifically, over half of these studies conceptualized identities as narratives (transition 54\%; higher education 63\%). In addition, there was a significant number of studies (38\%) exploring the transition between school and higher education that conceptualised identity as individual attributes (i.e., students decide to move choose mathematically demanding careers because of certain characteristics that they carry with them between practices). Possible reasons for these emphases and implications will be discussed in the following section. 


\section{Discussion}

The main goal of this article was to summarize how MLIs have been conceptualized and operationalized in mathematics education and to propose a model of the main dimensions that need to be considered when analysing and using/operationalizing definitions of MLIs. This summary can provide a shared language that could be used to tackle, and potentially bridge epistemological, theoretical and methodological disparities between traditions.

By systematically reviewing the literature, this paper has proposed a model which expresses how three dimensions [social/subjective, representational/enacted and change/stability] have been employed in the conceptualization and operationalization of MLI by researchers. As described in the results section, it is useful to consider how identity is defined, conceptualized and operationalized by examining how researchers solve the tensions between the poles of the three dimensions (intra-dimensionality) and how they relate/combine the defining features of different dimensions (inter-dimensionality). As we have highlighted, how one addresses these two issues carries implications in terms of how MLI has been previously researched methodologically.

In developing this model, we have had to overcome a "quantitative fallacy" in understanding the nature of an intra-dimensional relationship (i.e., that adopting more of one defining feature on a dimension always implies less of the other). Instead, we have opted to explore in detail how different poles on a dimension and between dimensions are articulated. For example, the two studies presented in the analysis example in table 1 considered subjective/social, representational/enacted and notions of change as features in their conceptualizations of MLI, but they were articulated differently depending on their intended purpose, methodological grounding and how they emphasised these features. For instance, in relation to their understanding of enacted aspects of identity, what differentiated these two studies was not how close they were to the enacted or to the representational poles in this dimension (i.e., a quantitative understanding of the dimension as defined by a dichotomy of the two poles), but how they defined the relationship between all the defining features. The enacted and social aspects in study 1 are constitutional elements of identity (identity is how we act and how we participate in social context). In contrast, in study 2 social participation gives information that needs to be negotiated in the 
form of representations (i.e the ability to participate and perform). Following this, both studies are examples of how tensions between intra-dimensional aspects are solved by using defining features of other dimensions (inter-dimensionality).

We believe that the model we present in this paper can be used both prospectively and retrospectively. Prospectively, it can allow researchers in early stages of their project development to consider these dimensions when defining their conceptualization of identity, thus increasing the coherence between research goals, operationalization of variables, and selection of instruments or methods to collect data.

Retrospectively, this model can be used as an analytic lens to understand individual studies, thus complementing a literature that has commonly explained variations in MLIs' definitions as a consequence of theoretical differences (Black, Mendick \& Solomon, 2008; Darragh, 2016; Stentoft \& Valero, 2009). For example, the review by Darragh (2016) grouped the existing research on MLIs into five groups: Participative, Narrative, Discursive, Psychoanalytic and Positional. When addressing how these groups of studies differed in their conceptualization of identity Darragh considered the authors' theoretical allegiances as the main grouping criteria. However, a limitation of this approach is that the same author or foundational text (e.g., Holland et al., 1998; Walkerdine, 1998; Wenger, 1998) is used in different groups of studies, thus suggesting a certain theoretical overlap between groups. This paper suggests that the understanding of theoretical overlap and differences can be advanced by considering how theoretical concepts are used and operationalized, and that such analysis is more effective when keeping in mind the social/subjective, representational/enacted and change/stability dimensions of MLIs.

As an example, ideas from Holland and colleagues (1998) were identified in studies that Darragh categorized as conceptualizing identities as participative, narrative and positional. Using our dimensional model it is possible to understand how Holland and colleagues' ideas are differently employed and operationalized in these three groups. Studies that focus on participative identities (what we called "identities as a relationship with a specific practice") use the concept of Figured World to understand shared meanings, activities and characters in a shared social context. In this sense, these studies emphasize Holland and colleagues' idea that identity can be understood as a subjective sense in a particular social 
context, with a clear emphasis on representations. The dimension of change, in these studies, is considered as a process in which social meanings are constructed. In contrast, studies that focus on narrative identities (what we called "identities as narratives") draw mainly on Holland's concept of figurative identities, identities that have to do with stories, "signs that evoke storylines or plots among generic characters" (Holland et al., 1998, p. 128). In these studies the emphasis is again on representations and subjective senses, but also on how these representations and senses are storied and change in time and not necessarily in relation to a specific shared practice. Even though here the social dimension is involved as meanings are socially produced and reproduced (in figured worlds), the main emphasis is on how these social products are used in individual storylines and plots, and not in the particular social practice that produces them. Finally, and also in contrast with the previous two groups of studies, some authors have used Holland et al. (1998) to understand what Darragh calls positional identities (what we called "identities as ways of acting”). In these studies there is an emphasis on enacted (and not representational) aspects of identity, and Holland et al. (1998) is used to understand how, while acting, individuals position themselves (through acts) with different entitlements according to how power is distributed in practice. Change, in these studies, is mainly analysed as the moment-by-moment unfolding of events. Therefore, when considering the dimensional model as a tool to compare these three groups of studies it is possible to argue that the main difference between them is not their theoretical approach, but how theory is used in practice. Using the social/subjective, representational/enacted and change/stability dimensions to understand how identities are operationalized allows us to see how the same concepts are used differently which then has consequences in terms of what such concepts become in a given analysis. More importantly, it provides an account of the methodological field for MLI since it fosters awareness not only of the ontological/epistemological foundations of MLI concepts, but also the potential ways such concepts are operationalised and the assumptions, norms and issues that this raises.

In contrast with previous reviews that have presented and evaluated the MLI literature critically (e.g., Darragh, 2016; Stentoft \& Valero, 2009), this review does not attempt to critique specific theoretical approaches, but instead it offers a model to identify potential limitations in the field. For example in relation to the social/subjective dimension, this 
review proposes that mathematical identity research owes much to subjective individual concepts, such as senses, self-beliefs, personal stories and affects. Ignoring this subjective aspect, by focusing only on social dimensions, limits our understanding of how particular selves are produced and how individual agency is implicated in such processes (Stetsenko \& Arievich, 2004). Similarly, even though the subjective aspect is central in exploring MLIs, focusing exclusively on this domain can lead to essentialist and un-contextualised notions of identities as attributes, without accounting for the influence of social elements (as noted by Atweh \& Cooper, 1995; Boaler, 2002). Research on MLIs needs to be aware of and make explicit the social genesis of students' relationship with mathematics, considering both proximal (e.g., parents, teachers and peers support and expectations, access to role models, etc.) and distal (e.g., distribution of opportunities, structures and institutional, etc.) influences. From this perspective, identity is better understood not as something an individual has, but as something an individual does socially (e.g., see Darragh's critique in her 2016 review).

In relation to the representational/enacted dimension, this review showed that there is a marked overemphasis in the literature on representational views of identity - based on semiotically mediated meanings - over enacted identities. The main limitation of this overemphasis is the tendency to neglect the study of the mechanisms of production and reproduction of identities with others in real contextual practices. It is interesting to note here that some researchers have conceptually, and operationally, addressed this limitation by defining narratives as identity performances or enactments (e.g., see Braathe \& Solomon, 2015; Darragh, 2015). Studies using this conceptualization have paid close attention to how different languages and discourses are used when interacting with the interviewer (e.g., Braathe \& Solomon, 2015) or how they are employed to position the self in relation to multiple others/voices (e.g., Lim, 2008; Solomon, 2012), thus allowing some insight into underlying mechanisms of production. Nevertheless, this perspective is not exempt of limitations, since very little attention is paid to how significant others engage and/or recognize these identities in the context of learning mathematics.

A final novel finding of this review is the description of large differences between studies that conceptualize and operationalize identity during school age (K-12), transition and higher education. Studies that explored MLIs during school age tended to emphasize 
practised and enacted views of identity, while those covering higher education tended to focus on representational and subjective forms of identity. This finding might be explained by differences in individuals' experiences in mathematics classrooms in these phases and/or by their different periods of development: changing capacities and changing social requirements during individuals' lives may change how identity is experienced and therefore, how it needs to be researched. For example, during puberty and adolescence new emerging forms of thinking change the way in which the individual relates to herself and others, becoming increasingly more self- aware and better able to use language to mediate behaviour and will (Vygotsky, 1998). In addition, the social requirement of committing to an educational and/or labour trajectory just before the transition to higher education (Erikson, 1968) may also engage students in the generation of narratives about their lives which can give meaning to their present and future choices (Smith, 2010). Due to these cognitive and social developmental milestones, it is no surprise that narratives become the methodological approach of choice in order to capture the construction of MLIs. Younger children, in contrast, have not fully developed such self-awareness and self-reflection dispositions or abilities, and therefore may find it more difficult to engage in narrative activity in ways that we (researchers) would easily recognise as such. Furthermore, it is possible that society does not expect young children to produce sophisticated representations of who they are, but rather expects them to become "industrious" by learning and adjusting to social norms (Erikson, 1968).

Elsewhere we have argued that the process of identity construction may look quite different at different developmental phases (Black et al., 2017) and therefore, in our view it makes "practical" sense that the study of MLIs focuses on enacted aspects during the primarysecondary phase and representational aspects during transition and higher education. However, such justification should be critically considered, for there is a danger in reducing the complexity of the development of MLIs due to limitations in our methodological tools or even social presuppositions. In consequence, future research could usefully consider ways of overcoming the methodological challenges of studying narrative aspects of identity during early childhood (primary education), as well as enacted and practised forms of identity during adulthood (higher education). A potentially useful approach here could be the transferring of methodologies used with primary students to explore enacted identities 
in older students (e.g., see the study of secondary students of Turner et al., 2013). Similarly, the use of methodologies that scaffold children's narrative ability, for example by employing pictures or concrete identity maps (Ali-Khan \& Siri, 2014; Black et al., 2017; Noland, 2006; Radovic et al., 2017), could help us to understand how they subjectively feel and experience the activity of doing mathematics.

Due to the growing popularity of the concept of MI, this review argues that studies need to carefully develop their conceptual and operational definitions of identities considering a number of existing conceptual frames. It also proposes that commonly reported "divergences" are an important source of limitations in the interpretation of empirical evidence. In consequence, an inclusive framework of the dimensions considered by the literature when defining and operationalizing MLIs can facilitate researchers' task of situating their own conceptualisations on the complexity of the concept. This framework can also allow researchers from different methodological and theoretical traditions to enter into a dialogue, dialogue that is necessary for the research community to move towards a conceptual coherence in mathematics learner identity research. 


\section{References}

Ali-Khan, C., \& Siry, C. (2014). Sharing seeing: Exploring photo-elicitation with children in two different cultural contexts. Teaching and Teacher Education, 37, 194-207.

Andersen, L., \& Ward, T. J. (2014). Expectancy-value models for the STEM persistence plans of ninth-grade, high-ability Students: A comparison between black, hispanic, and white students. Science Education, 98(2), 216-242.

Anderson, D.D., \& Gold, E. (2006). Home to school: Numeracy practices and mathematical identities. Mathematical Thinking and Learning, 8(3), 261-286.

Archer, L., Dewitt, J., Osborne, J., Dillon, J., Willis, B. \& Wong, B. (2012). Balancing acts: Elementary school girls' negotiations of femininity, achievement, and science. Science Education, 96(6), 967-989.

Atweh, B. \& Cooper, T. (1995). The construction of gender, social class and mathematics in the classroom. Educational Studies in Mathematics, 28, 293-310.

Axelsson, G.B. (2009). Mathematical identity in women: The concept, its components and relationship to educative ability, achievement and family support. International Journal of Lifelong Education, 28(3), 383-406.

Bishop, J.P. (2012). She's always been the smart one. I've always been the dumb one: Identities in the mathematics classroom. Journal For Research In Mathematics Education, 43(1), 34-74.

Black, L. (2004). Differential participation in whole-class discussions and the construction of marginalised identities. Journal of Educational Enquiry, 5(1), 34-54.

Black, L., Mendick, H. \& Solomon, Y. (Eds.) (2008). Mathematical relationships in education: Identities and participation. New York: Routledge.

Black, L., Williams, J., Hernandez-Martinez, P., Davis, P., Pampaka, M. \& Wake, G. (2010). Developing a 'leading identity': the relationship between students' mathematical identities and their career and higher education aspirations. Educational Studies in Mathematics, 73(1), 55-72.

Black, L., Wiliams, J., Choudry, S., Pickard-Smith, K. \& Ryan, B. (2017). Exploring the 'seeds' of disengagement: a methodological framework for researching young children's identifications with the formal school curriculum. Manuscript submitted for publication.

Boaler, J. (1999a). Participation, knowledge and beliefs: A community perspective on mathematics learning. Educational studies in mathematics, 40(3), 259-281.

Boaler, J. (1999b). Creating mathematical futures through an equitable teaching approach: The case of Railside School. Teachers College Record, 110(3), 608-645.

Boaler, J. (2002). Paying the price for " sugar and spice ": Shifting the analytical lens in equity research. Mathematical Thinking and Learning, 4(2-3), 127-144.

Boe, M.V. (2012). Science choices in Norwegian upper secondary school: What matters?. Science Education, 96(1), 1-20.

Braathe, H.J. \& Solomon, Y. (2015). Choosing mathematics: the narrative of the self as a 
site of agency. Educational Studies in Mathematics, 89(2), 151-166.

Brubaker, R., \& Cooper, F. (2000). Beyond "identity". Theory and society, 29(1), 1-47.

Campbell, T., Lee, H., Kwon, H., \& Kyungsuk, P. (2012). Student motivation and interests as proxies for forming STEM identities. Journal of the Korean Association for Science Education, 32(3), 532-540.

Chronaki, A. (2005). Learning about 'learning identities' in the school arithmetic practice: The experience of two young minority Gypsy girls in the Greek context of education. European Journal Of Psychology Of Education, 20(1), 61-74.

Cobb, P., Gresalfi, M. \& Hodge, L.L. (2009). An interpretive scheme for analyzing the identities that students develop in mathematics classrooms. Journal For Research In Mathematics Education, 40(1), 40-68.

Craig, T. S. (2013). Conceptions of mathematics and student identity: implications for engineering education. International Journal of Mathematical Education in Science and Technology, 44(7), 1020-1029.

Darragh, L. (2013). Constructing confidence and identities of belonging in mathematics at the transition to secondary school. Research in Mathematics Education, 15(3), 215-229.

Darragh, L. (2015). Recognising 'good at mathematics': using a performative lens for identity. Mathematics Education Research Journal, 27(1), 83-102.

Darragh, L. (2016). Identity research in mathematics education. Educational Studies in Mathematics, 93(1), 19-33.

de Abreu, G. (1995). Understanding how children experience the relationship between home and school mathematics. Mind, Culture, and Activity, 2(2), 119-142.

Eccles, J. (2009). Who am I and what am I going to do with my life? Personal and collective identities as motivators of action. Educational Psychologist, 44(2), 7889.

Empson, S.B. (2003). Low-performing students and teaching fractions for understanding: An interactional analysis. Journal For Research In Mathematics Education, 34(4), 305-343.

Epstein, D., Mendick, H. \& Moreau, M-P. (2010). Imagining the mathematician: young people talking about popular representations of maths. Discourse-Studies in the Cultural Politics of Education, 31(1), 45-60.

Erikson, E. (1968). Identity Youth and Crisis. New York: Norton \& Company.

Flores, M.A., \& Day, C. (2006). Contexts which shape and reshape new teachers' identities: A multi-perspective study. Teaching and teacher education, 22(2), 219232.

Hannula, M.S. (2012). Exploring new dimensions of mathematics-related affect: embodied and social theories. Research in Mathematics Education, 14(2), 137-161.

Hernandez, P.R., Schultz, P., Estrada, M., Woodcock, A., \& Chance, R. C. (2013). Sustaining optimal motivation: A longitudinal analysis of interventions to broaden 
participation of underrepresented students in STEM. Journal of educational psychology, 105(1), 89-107.

Heyd-Metzuyanim, E. (2013). The co-construction of learning difficulties in mathematicsteacher-student interactions and their role in the development of a disabled mathematical identity. Educational Studies in Mathematics, 83(3), 341-368.

Hodge, L. (2008). Student roles and mathematical competence in two contrasting elementary classes. Mathematics Education Research Journal, 20(1), 32-51.

Holland, D., Lachicotte, W. J., Skinner, D., \& Cain, C. (1998). Identity and agency in cultural worlds. Cambridge, Massachusetts: Harvard University Press.

Holmegaard, H.T., Madsen, L.M. \& Ulriksen, L. (2014). To choose or not to choose science: Constructions of desirable identities among young people considering a STEM higher education programme. International Journal of Science Education, $36(2), 186-215$.

Horn, I.S. (2008). Turnaround Students in High School Mathematics: Constructing identities of competence through mathematical worlds. Mathematics Thinking and Learning, 10(3), 201-239.

Lesko, A.C. \& Corpus, J.H. (2006). Discounting the difficult: How high math-identified women respond to stereotype threat. Sex Roles, 54(1-2), 113-125.

Lim, J.H. (2008). The road not taken: two African-American girls' experiences with school mathematics. Race, Ethnicity and Education, 11(3), 303-317.

McGee, E.O., Martin, D.B. (2011). You would not believe what I have to go through to prove my intellectual value! Stereotype management among academically successful black mathematics and engineering students. American Educational Research Journal, 48(6), 1347-1389.

Mendick, H. (2005). A beautiful myth? The gendering of being/doing 'good at maths'. Gender and Education, 17(2), 203-219.

Nasir, N.S., \& Cobb, P. (2007). Improving access to mathematics: Diversity and equity in the classroom. Multicultural Education Series. New York: Teachers College Press.

Nasir, N.S. \& Hand, V. (2008). From the court to the classroom: Opportunities for engagement, learning, and identity in basketball and classroom mathematics. Journal of the Learning Science, 17(2), 143-179.

Nivens, R.A., \& Otten, S. (2017). Assessing journal quality in mathematics education. Journal for Research in Mathematics Education, 48(4), 348-368.

Noland, C.M. (2006). Auto-photography as research practice: Identity and self-esteem research. Journal of research Practice, 2(1), 1-19.

Pronin, E., Steele, C.M. \& Ross, L. (2004). Identity bifurcation in response to stereotype threat: Women and mathematics. Journal of Experimental Social Psychology, $40(2), 152-168$.

Radovic D., Black L., Salas, C.E., Williams J. (2017). Being a girl mathematician: Diversity of positive mathematical identities in a secondary classroom. Journal for 
Research of Mathematics Education 48(4), 434-464.

Sfard, A. (2006). Telling ideas by the company they keep: A response to the critique by Mary Juzwik. Educational Researcher, 35(9), 22-27.

Sfard, A., \& Prusak, A. (2005). Telling identities: In search of an analytic tool for Investigating Learning as a Culturally Shaped Activity. Educational Researcher, 34(14), 14-22.

Smith, C. (2010). Choosing more mathematics: happiness through work? Research in Mathematics Education, 12(2), 99-115.

Solomon, Y. (2007). Not belonging? What makes a functional learner identity in undergraduate mathematics? Studies in Higher Education, 32(1), 79-96.

Solomon, Y. (2008). Mathematical literacy: Developing identities of inclusion. London and New York: Routledge.

Solomon, Y. (2012). Finding a voice? Narrating the female self in mathematics. Educational Studies in Mathematics, 80(40574), 171-183.

Solomon, Y., Lawson, D. \& Croft, T. (2011). Dealing with 'fragile identities': resistance and refiguring in women mathematics students. Gender and Education, 23(5), 565-583.

Stentoft, D., \& Valero, P. (2009). Identities-in-action. Nordic Studies in Mathematics Education, 14(3), 55-77.

Stetsenko, A., \& Arievitch, I.M. (2004). The self in cultural-historical activity theory. Reclaiming the unity of social and individual dimensions of human development. Theory \& Psychology, 14(4), 475-503.

Strauss, A., \& Corbin, J. (1998). Basics of qualitative research. Thousand Oaks, CA: Sage.

Sutherland, L., Howard, S., \& Markauskaite, L. (2010). Professional identity creation: Examining the development of beginning preservice teachers' understanding of their work as teachers. Teaching and Teacher Education, 26(3), 455-465.

Tate, E.D., \& Linn, M.C. (2005). How does identity shape the experiences of women of color engineering students? Journal of Science Education and Technology, 14(56), 483-493.

Thomas, J., \& Harden, A. (2008). Methods for the thematic synthesis of qualitative research in systematic reviews. BMC Medical Research Methodology, 8(1), 45.

Turner, E., Dominguez, H., Maldonado, L. \& Empson, S. (2013). English learners' participation in mathematical discussion: Shifting positionings and dynamic identities. Journal For Research In Mathematics Education, 44(1), 199-234.

Varela, M., Martin, D.B., \& Kane, J.M. (2012). Content learning and identity construction: A framework to strengthen African American students' mathematics and science learning in urban elementary schools. Human Development, 55(5), 319-339.

Vygotsky, L.S. (1998). Child development, The collected works of L. S. Vygotsky, Vol. 5. New York: Plenum. 
Walls, F. (2009). Mathematical subjects: Children talk about their mathematics lives.

Dordrecht, Heidelberg, London and New York: Springer.

Walkerdine, V. (1998). Counting girls out: Girls and mathematics. Second edition. London and New York: Routledge Falmer.

Wenger, E. (1998). Communities of practice: Learning, meaning, and identity. Cambridge: Cambridge university press.

Wetherell, M. (2010). The field of identity studies. In M. Wetherell \& C. Mohanty (Eds). The SAGE handbook of identities (pp. 3-26). London, California, New Delhi and Singapore: Sage publications. 